\title{
sciendo
}

\section{THE EFFECT OF SILYBUM MARIANUM SEED, THYMUS VULGARIS, AND ROSMARINUS OFFICINALIS POWDERS IN ALLEVIATING THE RISKS OF AFLATOXIN B1 IN YOUNG BROILER CHICKS}

\author{
Hamid Raei ${ }^{1 \bullet}$, Ramin Najafi ${ }^{2}$, Mohammad Amir Karimi Torshizi ${ }^{1}$, Seyyed Meysam Abtahi Froushani ${ }^{3}$, \\ Fatemeh Azari Ghaleh Joogh ${ }^{2}$ \\ ${ }^{1}$ Department of Poultry Science, Faculty of Agriculture, Tarbiat Modares University, Jalal Ale Ahmad, \\ Nasr, Tehran, Iran \\ ${ }^{2}$ Department of Animal Science, Faculty of Agriculture, Urmia University, Urmia, Iran \\ ${ }^{3}$ Department of Microbiology, Faculty of Veterinary Medicine, Urmia University, Urmia, Iran \\ •Corresponding author: Hamidraei1368@yahoo.com
}

\begin{abstract}
This investigation was aimed to evaluate the effects of Silybum marianum seed, Thymus vulgaris, and Rosmarinus officinalis powders and their combination in alleviating the risks of aflatoxin B1 (AFB1) in young broiler chicks. One-day-old Ross 308 male broiler chickens were allocated to 6 experimental groups from $\mathrm{d} 1$ to 21 . The experimental dietary groups included: Negative control (NC) received the basal diet, Positive control (PC) containing 2 mg AFB1/kg diet; Positive control $+10 \mathrm{~g} / \mathrm{kg}$ diet of Silybum marianum seed (SMS); Positive control $+10 \mathrm{~g} / \mathrm{kg}$ diet of Thymus vulgaris (TV); Positive control $+5 \mathrm{~g} / \mathrm{kg}$ diet of Rosmarinus officinalis (RO); Positive control $+10 \mathrm{~g} / \mathrm{kg}$ diet of SMS $+10 \mathrm{~g} / \mathrm{kg}$ diet of TV $+5 \mathrm{~g} / \mathrm{kg}$ diet of $\mathrm{RO}$ as a blend of herbs (BH). There was no difference between feed intake and body weight gain among the experimental groups $(\mathrm{P}>0.05)$. In contrast, the feed conversion rate $(\mathrm{FCR})$ in $\mathrm{NC}$ and $\mathrm{SMS}$ groups was lower than in other groups $(\mathrm{P}<0.05)$. Calcium levels and high-density lipoprotein cholesterol (HDL) were lower in serum samples, but the activity of alanine aminotransferase (ALT) and aspartate aminotransferase (AST) were higher in $\mathrm{PC}$ chickens $(\mathrm{P}<\mathbf{0 . 0 5})$. Increase in the thigh muscle malondialdehyde (MDA) in chickens fed AFB1 was significantly reduced in the NC, SMS, and BH chickens $(\mathrm{P}<0.05)$. Chickens of $\mathrm{NC}$ and SMS groups showed the highest response to respiratory burst of heterophil (NBT assay) and lymphocyte proliferation assays (MTT assay) $(\mathrm{P}<\mathbf{0 . 0 5})$. In conclusion, the addition of studied herbs, especially SMS, to the AFB1 contaminated diet could have a protective effect against aflatoxicosis in broiler chickens.
\end{abstract}

Key words: antioxidant, broiler immune system, herbal medicine, mycotoxin, performance

Aflatoxin B1 (AFB1) is a well-established, secondary metabolite of the fungi, such as Aspergillus flavus and Aspergillus parasiticus. This toxin is considered the 
primary contamination for grains and typical foods, as well as feed ingredients in the world especially in Africa, Asia, and Latin America (Solcan et al., 2013; Ditta et al., 2019). Many animal species, such as poultry, are subject to aflatoxins' hepatotoxic, hepatocarcinogenic, mutagenic, and teratogenic effects (Tedesco et al., 2004). Aflatoxicosis or aflatoxin poisoning in broilers leads to a noticeable reduction in feed intake, growth rate, as well as feed utilization, and survival rate (Tedesco et al., 2004; Bailey et al., 2006). Even though the fungi elimination from food and feedstuff is of significant importance, a high concentration of mycotoxins, particularly aflatoxins, can still be observed. For many years, employing different approaches to minimize aflatoxins' toxic effects has been the subject of concern among manufacturers, researchers, and governments (Oguz et al., 2018). In this case there have been reported compounds such as zeolite, sodium bentonite, and mannose oligosaccharide which have the ability to neutralize the adverse effects of aflatoxin B1 (Malekinezhad et al., 2020). Biological methods are considered to reduce mycotoxins in poultry diets (Rasouli-Hiq et al., 2016).

Nowadays, medicinal plants and their compounds have captured significant attention in the poultry industry due to laying the foundation for the enhancement in the performance, along with the improvement in the quality of the feed. These compounds are used either as dry or aqueous extracts or essential oils as additives in the animal diet, such as poultry (Da Silva Cardoso et al., 2016). Recently, a review pointed out that some medicinal plants have reduced the toxic effects of aflatoxins in the feed (Loi et al., 2020). Milk thistle (Silybum marianum) is one of the major medicinal herbs belonging to the Asteraceae family, native to North Africa and the Mediterranean area (Pepping, 1999). Silymarin phytosomes, derived from milk thistle seeds, have been demonstrated to be beneficial to broiler in the course of aflatoxicosis (Tedesco et al., 2004). Thyme, Thymus vulgaris L., is an important aromatic, medicinal plant among the Lamiaceae family in Europe, Asia, North Africa, as well as North America (Naghdi Badi et al., 2004). Thymol and carvacrol are the major compounds of garden thyme (Chen et al., 2014). As the main active component, the volatile phenolic thyme oils have antibacterial, antimycotic, antioxidative, natural food preservative, and anti-aging properties (Naghdi Badi et al., 2004). Rosemary (Rosmarinus officinalis L.), a member of the Lamiaceae family, is originated from the Mediterranean region. The phyto-compounds of Rosmarinus officinalis L. have several pharmacological activities, such as antimicrobial, antioxidant, cognition improving, cancer chemoprevention, and DNA-protective effects (Tsukamoto et al., 1995). Components, such as minerals, tannins, essential oil, ursolic acid, alkaloids, vitamins, flavonol compounds, and other biologically active metabolites, are found in rosemary leaves. Not only is rosemary available commercially as an antioxidant in Europe and the United States, but also it is widely used in food processing (Manafi et al., 2014 a). Although herbs' application as antioxidant compounds has been reported in recent studies, there is still limited information in this area. Moreover, as previous studies reported, aflatoxin toxicity has an inverse correlation with age; therefore, young chickens are more sensitive to aflatoxins' toxic effects (Hussain et al., 2010). Due to the presence of active ingredients in Silybum marianum, Thymus vulgaris, and Rosmarinus officinalis and based on results of previous studies, it is hypoth- 
esized that these herbs have positive effects against aflatoxins. Consequently, this experiment aims at investigating the effect of Silybum marianum seed, Thymus vulgaris, and Rosmarinus officinalis powders on the performance, some metabolites of blood, lipid peroxidation and ferric reducing antioxidant power (FRAP) in thigh meat, and the broilers immune system response, receiving a diet contaminated with aflatoxin B1.

\section{Material and methods}

\section{Birds and experimental design}

Two hundred and forty Ross 308 d-old male broiler chicks were divided, based on a completely randomized design, into 6 experimental groups and five replicates (10 chicks per replicate) for 21 days. The initial body weight of the chicks was $43 \mathrm{~g} /$ bird. During the experiment, all the environmental conditions were the same for the treatments, receiving food and water, ad libitum, from hatch to $\mathrm{d} 21$. Experimental groups included: (1) Negative control (NC) with the basal diet, (2) Positive control (PC) containing $2 \mathrm{mg} \mathrm{AFB1} / \mathrm{kg}$ diet, (3) Positive control $+10 \mathrm{~g} / \mathrm{kg}$ diet of Silybum marianum seed (SMS), (4) Positive control $+10 \mathrm{~g} / \mathrm{kg}$ diet of Thymus vulgaris (TV), (5) Positive control $+5 \mathrm{~g} / \mathrm{kg}$ diet of Rosmarinus officinalis (RO), (6) Positive control $+10 \mathrm{~g} / \mathrm{kg}$ diet of SMS $+10 \mathrm{~g} / \mathrm{kg}$ diet of TV $+5 \mathrm{~g} / \mathrm{kg}$ diet of RO as blend of herbs $(\mathrm{BH})$. The selection of aflatoxin B1 and herbs doses employed in this experiment was based on previous studies (Zhao et al., 2010; Chand et al., 2011; Hamzawy et al., 2012). The herbs utilized in the experiment were freshly harvested (whole aerial organs of RO and TV and the seeds of SMS), and dried, added to the diet as additive. The Ross 308 guidelines were employed to provide all of the broiler chicks' nutritional needs (Table 1) (Ross Broiler Nutrition Specifications, 2014). The experimental groups were reared on the floor during the whole period. At the beginning of the experiment, the house's temperature was $32-33^{\circ} \mathrm{C}$, which gradually decreased to $29-28^{\circ} \mathrm{C}$ following the first week. The lighting period was from $23 \mathrm{~h}$ light: $1 \mathrm{~h}$ dark in the first week to $20 \mathrm{~h}$ light: $4 \mathrm{~h}$ dark in the third week. The Urmia University approved the animal care and experimental design under the approval number of IR-UU-AEC-278/DA3.

Table 1. Ingredients and calculated nutrients of experimental diets

\begin{tabular}{l|c|c}
\hline \multicolumn{1}{c|}{ Ingredients } & $\begin{array}{c}\text { Starter diet } \\
(1-10)\end{array}$ & $\begin{array}{c}\text { Grower diet } \\
(11-21)\end{array}$ \\
\hline \multicolumn{1}{c|}{1} & 2 & 3 \\
\hline Maize & 50.56 & 55.07 \\
Soybean meal $(44 \% \mathrm{CP})$ & 40.40 & 37.31 \\
Rice $^{1}$ & 0.69 & 0.69 \\
Soybean oil & 2.95 & 2.76 \\
Dicalcium phosphate & 2.25 & 1.95 \\
\hline
\end{tabular}


Table 1 - contd.

\begin{tabular}{lccc}
\hline & 1 & 2 & 3 \\
\hline Calcium carbonate & 1.49 & 0.97 \\
L-Lysine & 0.28 & 0.09 \\
DL-Methionine & 0.35 & 0.25 \\
L-Threonine & 0.12 & 0.03 \\
Sodium bicarbonate & 0.16 & 0.06 \\
Vitamin and Mineral premix ${ }^{2}$ & 0.50 & 0.51 \\
Common salt & 0.25 & 0.31 \\
Total & 100 & 100 \\
Calculated nutrient content & & \\
dry matter (\%) & 85.42 & 89.20 \\
ME (MJ/kg) & 12.13 & 12.34 \\
CP (\%) & 22.66 & 21.34 \\
Ca (\%) & 1.13 & 0.87 \\
Available P (\%) & 0.48 & 0.43 \\
K (\%) & 0.95 & 0.90 \\
Na (\%) & 0.16 & 0.16 \\
Cl (\%) & 0.23 & 0.23 \\
Lys (\%) & 1.45 & 1.24 \\
Met + Cys (\%) & 1.04 & 0.91 \\
Trp (\%) & 0.27 & 0.26 \\
Thr (\%) & 0.96 & 0.84 \\
\hline
\end{tabular}

${ }^{1}$ Rice was contaminated by aflatoxin B1 used in the treatment groups.

${ }^{2}$ Vitamins and Mineral premix provided the following per kilogram of diet: Retinol, 9000 IU; Tocopherolacetate, 18; Cyanocobalamin, $15 \mathrm{mg}$; Riboflavin, $6.6 \mathrm{mg}$; Calcium pantothenic acid, $10 \mathrm{mg}$; Niacin, $30 \mathrm{mg}$; Choline, $500 \mathrm{mg}$; Biotin, $1 \mathrm{mg}$; Thiamin, $8.1 \mathrm{mg}$; Pyridoxine, $3 \mathrm{mg}$; Folic acid, $1 \mathrm{mg}$; Menadione vitamin, $2 \mathrm{mg}$; Antioxidant (Ethoxyquin), 100 mg; Mn, 100 mg; Zn, 50 mg; Fe, 50 mg, Cu, 10 mg; I, 1 mg; Se, 0.2 mg.

\section{Aflatoxin B1 production}

As described by Shotwell et al. (1966), Aspergillus flavus PTCC-5004 was purchased from the Iranian Research Organization for Science and Technology to produce aflatoxins (Tehran, Iran). For initial growth, the Sabouraud dextrose agar (SDA) medium was utilized to culture the Aspergillus flavus. The cultures were incubated at $28^{\circ} \mathrm{C}$ for five days. Afterward, fungal spores were suspended, adding $5 \mathrm{ml}$ of $1 \%$ Triton X-100 per plate. Erlenmeyer flasks were used for the mass culture of Aspergillus flavus on rice grains to produce a mg quantity of aflatoxin B1. $100 \mathrm{~g}$ rice and $60 \mathrm{ml}$ distilled water were added to the flasks, mixed with a shaker for 2 hours. The flasks were autoclaved at $15 \mathrm{psi}$ and $121^{\circ} \mathrm{C}$ for $15 \mathrm{~min}$ and cooled. Under sterile conditions, $2 \mathrm{ml}$ of the spores' suspension containing $6.5 \times 10^{6}$ spores $/ \mathrm{ml}$ was inoculated into flasks, which were incubated for 14 days at $28^{\circ} \mathrm{C}$. After the rice was contaminated during this time, the flasks were autoclaved at $15 \mathrm{psi}$ and $121^{\circ} \mathrm{C}$ for 15 minutes. According to the Official Analytical Chemists (AOAC, 2000) guideline for aflatoxins 
in food and feeds (Romer minicolumn method, Method 975.36), the contaminated rice was prepared and milled, and its AFBs content was determined by HPLC (highpressure liquid chromatography). The HPLC system (Waters, USA) was fitted with fluorescence detector model 2475 (excitation $365 \mathrm{~nm}$ and emission $418 \mathrm{~nm}$ ) and a C18 guard and column $(150 \times 4.6 \mathrm{~mm})$. Water, acetonitrile, and methanol $(60$ : $30: 10, \mathrm{~V}: \mathrm{V}: \mathrm{V}$ ) was used as the mobile phase with the flow rate of $1 \mathrm{ml} / \mathrm{min}$ (ElNezami et al., 1998). After determining AFB1 concentration in contaminated rice, it was incorporated into the starter and grower diets to provide the desired amounts of $2 \mathrm{mg}$ AFB $1 / \mathrm{kg}$ feed. Table 2 presents the aflatoxin levels measured in diets before the addition of contaminated rice.

Table 2. Aflatoxins content in basal diet

\begin{tabular}{l|c|c|c|c|c|c|c}
\hline \multirow{2}{*}{ Diets } & \multirow{2}{*}{$\begin{array}{c}\text { Number } \\
\text { of samples }\end{array}$} & \multirow{2}{*}{ Replicate } & \multicolumn{5}{|c}{ Aflatoxins $(\mu \mathrm{g} / \mathrm{kg})$} \\
\cline { 4 - 8 } & & & AFB1 & AFB2 & AFG1 & AFG2 & Total \\
\hline Starter diet & 7 & 5 & 11.26 & 1.62 & ND $^{1}$ & ND & 12.88 \\
Grower diet & 7 & 5 & 12.20 & 2.47 & ND & ND & 14.67 \\
\hline
\end{tabular}

${ }^{1} \mathrm{ND}$, not detected.

Limit of detection (LOD), $0.04 \mu \mathrm{g} / \mathrm{kg}$; Limit of quantification (LOQ), $0.09 \mu \mathrm{g} / \mathrm{kg}$.

\section{Performance and blood parameters}

Chicks were weighed at days $0,7,14$, and 21 to calculate their weight gain. Feed intake was measured weekly. Mortality was monitored daily to regulate the feed conversion ratio (FCR).

At the end of the experiment, cutting the jugular vein and blood samples, one chick from each replicate was sacrificed, collected to determine serum parameters. Blood was centrifuged for $15 \mathrm{~min}$ at $3000 \mathrm{rpm}$, and the sera were gathered and preserved at $-20^{\circ} \mathrm{C}$ until submitted for biochemical analysis. The individual serum samples evaluation was carried out for uric acid, total protein, low-density lipoprotein cholesterol (LDL), high-density lipoprotein cholesterol (HDL), alanine aminotransferase (ALT), $\gamma$-glutamyl transferase (GGT), aspartate aminotransferase (AST), phosphorus and calcium by a spectrophotometric method using commercially available kits (Pars Azmun, Iran).

\section{Lipid peroxidation and ferric reducing antioxidant power (FRAP) assays in thigh meat}

As explained by Botsoglou et al. (1994), lipid peroxidation was estimated by monitoring the formed malondialdehyde (MDA) using thiobarbituric acid-reactive substances (TBARS). The malondialdehyde (MDA) level was reported in nmol MDA per each mg of meat samples. The FRAP (ferric reducing antioxidant power) assay was used to evaluate the total antioxidant capacity of the chickens' thigh muscles (Benzie and Strain, 1996).

\section{Immune system responses}

Polymorphonuclear heterophil and lymphocytes were isolated from normal chickens employing the indicated modifications in previously described procedures 
(Brooks et al., 1996) on day 21 of the experiment. In brief, whole venous blood was gathered in sodium citrate $(0.129 \mathrm{M}$; $\mathrm{pH} 6.5 ; 9: 1, \mathrm{v} / \mathrm{v})$, diluted in RPMI 1640 (Roswell Park Memorial Institute, Gibco/Life Technologies Inc., USA) (1:1) on a Ficoll-Hypaque (Sigma-Aldrich, USA) gradient. After centrifugation at $400 \mathrm{~g}$ for 30 minutes, the mononuclear cell layer and the plasma were gently taken out, using a Pasteur pipette, added to the warm medium to wash off any remaining platelets. The cells were then pre-incubated for 2 hours at $37^{\circ} \mathrm{C}$ in a moist atmosphere containing $5 \%$ of $\mathrm{CO}_{2}$. This method supported monocytes' adherence to the culture plate, where the non-adherent lymphocytes were eliminated, vigorously washing three times with an ice-cold medium.

Besides, the contaminant erythrocytes were removed by hypotonic lysis to isolate heterophils. The heterophils were counted in a Neubauer chamber (Sigma-Aldrich, USA). Trypan blue dye exclusion method was employed to examine the cells' viability (Gibco/Life Technology Inc., USA). After this procedure, the purity of live neutrophils was $94 \%$.

\section{Respiratory burst of the heterophils (NBT assay)}

After a challenge with opsonized $E$. coli isolated, the reactive oxygen species (ROS) intracellular formation was monitored by NBT (Nitro blue tetrazolium chloride, Sigma-Aldrich, USA) reduction, as previously described by Choi et al. (2006). The heterophils $\left(1 \times 10^{6}\right.$ cells $\left./ \mathrm{mL}\right)$ were admixed with $0.1 \%$ NBT in phosphatebuffered saline (Sigma-Aldrich, USA) ( $\mathrm{pH} 7.4)$, as well as heat-killed opsonized yeast $\left(1 \times 10^{6} \mathrm{cells} / \mathrm{ml}\right)$. The mixture was cultured at $37^{\circ} \mathrm{C}$ for $30 \mathrm{~min}$. The unused NBT was eliminated by washing. The reduced dye was extracted in $\mathrm{KOH}$ (2 M, Merck, Germany) and DMSO (dimethyl sulfoxide, Sigma-Aldrich, USA) and quantitated at $520 \mathrm{~nm}$.

\section{Lymphocyte proliferation assay (MTT assay)}

The isolated lymphocytes were cultured in 96-well flat-bottomed plates $\left(1 \times 10^{5}\right.$ cells/100 $\mu \mathrm{l} /$ well), pulsed with phytohemagglutinin (Sigma-Aldrich, USA) either at a final concentration of $5 \mu \mathrm{g} / \mathrm{ml}$ or a medium alone. After 72 hours, $20 \mu \mathrm{l}$ of the MTT (3-[4,5-dimethylthiazole-2-yl]-2,5-diphenyl tetrazolium bromide (Sigma-Aldrich, USA) solution (with the final concentration of $5 \mathrm{mg} / \mathrm{ml}$ ) was poured into each well, cultured at $37^{\circ} \mathrm{C}$ for 4 hours. Afterward, $150 \mu \mathrm{l}$ of DMSO was added to each well, vigorously shaken to dissolve the formazan crystal actively. A microplate reader read the optical density (OD) at $550 \mathrm{~nm}$ (Dynatech, Germany). All of the experiments were executed in triplicate, reported as the proliferation index (PI) calculated according to the ratio of $\mathrm{OD}_{550}$ of the pulsed cells with phytohemagglutinin to $\mathrm{OD}_{550}$ of the non-pulsed cells (Shushtari and Abtahi Froushani, 2017).

\section{Total antibody}

Employing a modification indicated in the previously described procedures, the total antibody was extracted from the plasma of blood (Bollineni et al., 2015). In brief, the total proteins in blood plasma were precipitated with $100 \%$ saturated ammonium sulfate, followed by variable solubilization in $45 \%$ and $40 \%$ saturated ammonium sulfate solutions. After dialysis, the antibodies final concentration was determined, utilizing the Bradford method. 


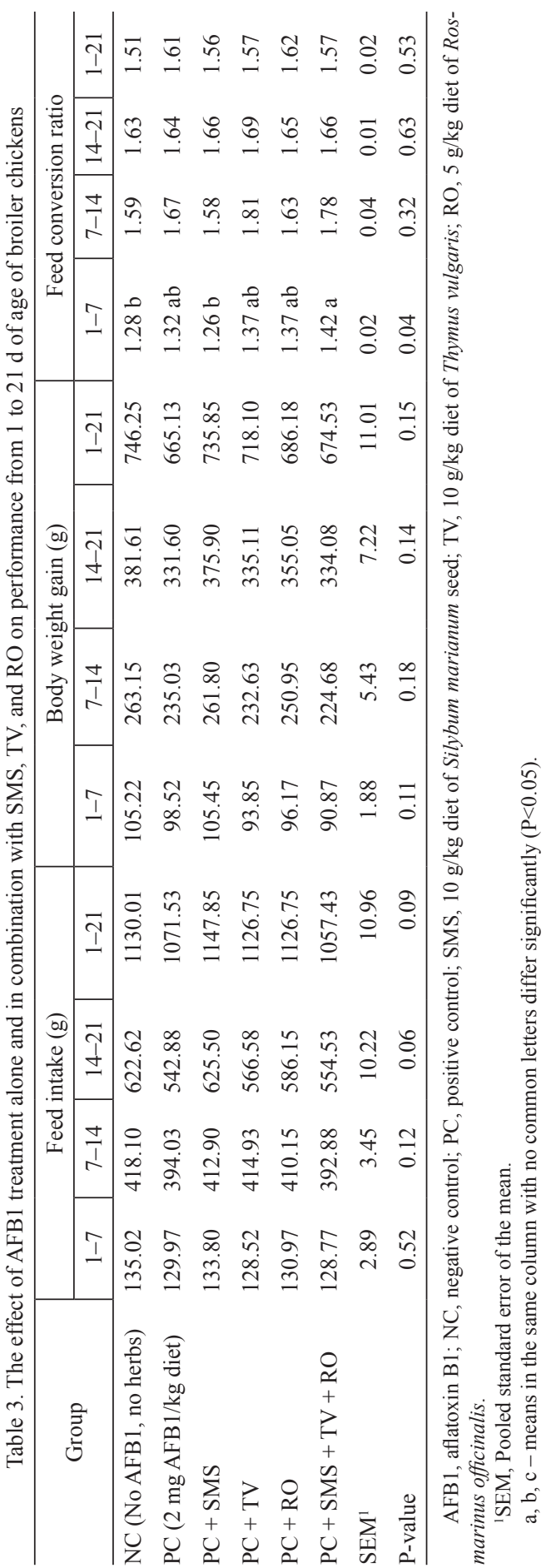




\section{Statistical analysis}

One-way analyses of variances were performed using ANOVA procedure of Statistical Analysis System (SAS, 9.1.3). The normality of all data was examined by univariate procedure and normal statement, and Shapiro and Wilk test. The homogeneity of variance was tested by Levene's test. Moreover, the treatment methods were compared using Duncan's multiple range test, and the obtained results were statistically significant concerning the probability level of 0.05 , according to the statistical model:

$$
Y_{i j}=\mu+X_{i}+e_{i j}
$$

In which $Y_{i j}$ is observation $\mathrm{j}$ of experimental unit subjected to treatments $\mathrm{i}$; $\mu$, the population mean; $X_{i}$ is the effect of $i^{t h}$ treatment, and $e_{i j}$ is the experimental error.

\section{Results}

\section{Performance of broiler chickens}

The experimental groups' effect on body weight gain, feed conversion rate, and feed intake is indicated in Table 3. According to this table, there were no significant discrepancies between feed intake and body weight gain $(\mathrm{P}>0.05)$. The FCR between 0 and $7 \mathrm{~d}$ was lower for the SMS group $(\mathrm{P}<0.05)$, while chickens receiving aflatoxin $\mathrm{B} 1$ with a blend of herbs $(\mathrm{BH})$ demonstrated the highest FCR $(\mathrm{P}<0.05)$. Nevertheless, the FCR was not affected by the treatments in the next weeks $(\mathrm{P}>0.05)$.

\section{Serum biochemical parameters}

Blood biochemistry analyses are provided in Table 4. Chicks fed on aflatoxin B1 contaminated feed alone (PC group) led to the significantly declined serum calcium and HDL, as well as increased ALT and AST activity $(\mathrm{P}<0.05)$. Compared with the PC chicks, adding SMS, TV, and RO to the aflatoxin B1 contaminated feed enhanced the levels of calcium and HDL, reducing the ALT and AST activity. SMS had the best performance in reducing ALT and AST activity among the experimental herbs. The case studies indicated no considerable variations in total serum protein, LDL, uric acid, and GGT levels $(\mathrm{P}>0.05)$. The discrepancy between total protein values was not significant $(\mathrm{P}=0.07)$, despite being lower in the $\mathrm{PC}$ group compared with other groups.

\section{Lipid peroxidation and ferric reducing antioxidant power (FRAP) in thigh meat}

As indicated in Table 5, the AFB1 treatment gave rise to the enhancement in thigh muscle's MDA concentration in the $\mathrm{PC}$ chickens $(\mathrm{P}<0.05)$. At the same time, the addition of SMS, TV and, RO together (or SMS alone) to the aflatoxin B1 contaminated feed successfully restored the lipid peroxidation in the thigh muscle of chickens $(\mathrm{P}<0.05)$. There was no remarkable discrepancy among the experimental groups for the thigh muscle's FRAP levels $(\mathrm{P}>0.05)$. 


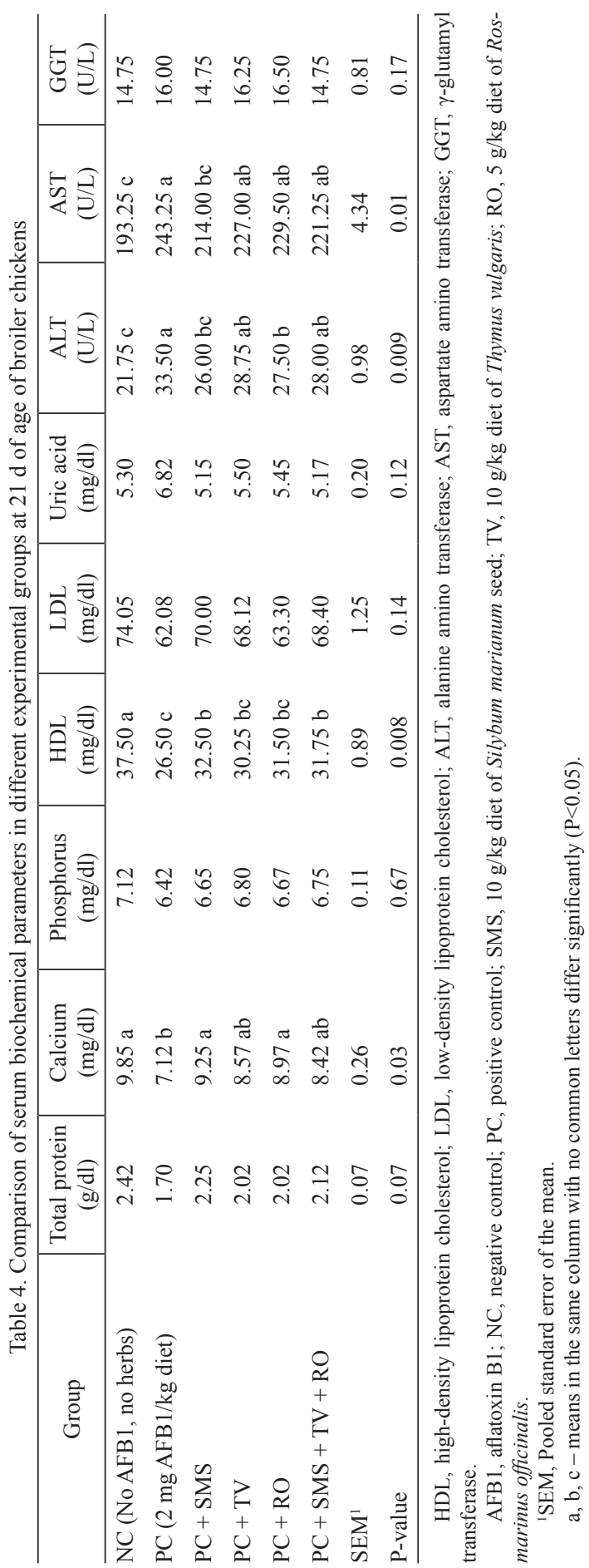


Table 5. The effect of AFB1 treatment alone and in combination with SMS, TV, and RO on malondialdehyde (MDA) concentration and ferric reducing antioxidant power (FRAP) level of thigh muscle in broilers chickens at 21 days of age

\begin{tabular}{l|c|c}
\hline \multicolumn{1}{c|}{ Group } & $\begin{array}{c}\text { MDA } \\
(\mathrm{nmol} / \mathrm{mg} \text { protein })\end{array}$ & $\begin{array}{c}\mathrm{FRAP}^{2+} \\
\left(\mu \mathrm{M} \text { of } \mathrm{Fe}^{2+} / \mathrm{g}\right)\end{array}$ \\
\hline NC (No AFB1, no herbs) & $0.178 \mathrm{~b}$ & 0.377 \\
PC (2 mg AFB1/kg diet) & $0.230 \mathrm{a}$ & 0.380 \\
PC + SMS & $0.179 \mathrm{~b}$ & 0.395 \\
PC + TV & $0.196 \mathrm{ab}$ & 0.405 \\
PC + RO & $0.208 \mathrm{ab}$ & 0.377 \\
PC + SMS + TV + RO & $0.187 \mathrm{~b}$ & 0.365 \\
SEM & 0.01 & 0.01 \\
P-value & 0.04 & 0.25 \\
\hline
\end{tabular}

AFB1, aflatoxin B1; NC, negative control; PC, positive control; SMS, $10 \mathrm{~g} / \mathrm{kg}$ diet of Silybum marianum seed; TV, $10 \mathrm{~g} / \mathrm{kg}$ diet of Thymus vulgaris; RO, $5 \mathrm{~g} / \mathrm{kg}$ diet of Rosmarinus officinalis.

MDA, malondialdehyde; FRAP, ferric reducing antioxidant power.

'SEM, Pooled standard error of the mean.

$\mathrm{a}, \mathrm{b}, \mathrm{c}-$ means in the same column with no common letters differ significantly $(\mathrm{P}<0.05)$.

\section{Immune system responses}

Table 6 demonstrates the experimental groups' effects on immune system response in broiler chicks. Diet did not play a large part in its influence on the total antibody of chicks' serum $(\mathrm{P}>0.05)$. However, compared with the NC, SMS, and BH groups, PC chicks had a lower response for NBT and MTT assays $(\mathrm{P}<0.0001)$.

Table 6. The effect of AFB1 treatment alone and in combination with SMS, TV, and RO on immune parameters including total antibody level, lymphocyte proliferation response (MTT) and respiratory burst in heterophil (NBT) of broilers chickens at 21 days of age

\begin{tabular}{l|c|c|c}
\hline \multicolumn{1}{c}{ Group } & $\begin{array}{c}\text { Total antibody } \\
(\mathrm{mg} / \mathrm{dl})\end{array}$ & $\begin{array}{c}\text { MTT } \\
(\mathrm{PI})^{1}\end{array}$ & $\begin{array}{c}\text { NBT } \\
(\mathrm{OD})^{2}\end{array}$ \\
\hline NC (No AFB1, no herbs) & 1.394 & $2.456 \mathrm{a}$ & $0.871 \mathrm{a}$ \\
PC (2 mg AFB1/kg diet) & 1.179 & $1.739 \mathrm{~b}$ & $0.390 \mathrm{c}$ \\
PC + SMS & 1.315 & $2.537 \mathrm{a}$ & $0.700 \mathrm{~b}$ \\
PC + TV & 1.387 & $1.688 \mathrm{~b}$ & $0.454 \mathrm{c}$ \\
PC + RO & 1.353 & $1.866 \mathrm{~b}$ & $0.500 \mathrm{c}$ \\
PC + SMS + TV + RO & 1.494 & $2.351 \mathrm{a}$ & $0.820 \mathrm{ab}$ \\
SEM & 0.09 & 0.08 & 0.04 \\
P-value & 0.96 & $<.0001$ & $<.0001$ \\
\hline
\end{tabular}

${ }^{1} \mathrm{PI}$, proliferation index calculated according to the ratio of $\mathrm{OD}_{550}$ of pulsed cells with phytohemagglutinin to $\mathrm{OD}_{550}$ of non-pulsed cells.

${ }^{2} \mathrm{OD}$, optical density at $550 \mathrm{~nm}$ was read by a microplate reader.

AFB1, aflatoxin B1; NC, negative control; PC, positive control; SMS, $10 \mathrm{~g} / \mathrm{kg}$ diet of Silybum marianum seed; TV, $10 \mathrm{~g} / \mathrm{kg}$ diet of Thymus vulgaris; RO, $5 \mathrm{~g} / \mathrm{kg}$ diet of Rosmarinus officinalis.

${ }^{3} \mathrm{SEM}$, Pooled standard error of the mean.

$\mathrm{a}, \mathrm{b}, \mathrm{c}-$ means in the same column with no common letters differ significantly $(\mathrm{P}<0.05)$. 


\section{Discussion}

As a general result of aflatoxins' presence in the feed ingredients, farm production parameters such as feed intake, feed conversion, weight gain, reproductive performance of the birds are affected. Also, these toxins can be introduced to the human food chain (Nakavuma et al., 2020). In current study, growth performance was not subject to experimental groups considerably. Da Silva Cardoso et al. (2016) reported no substantial influence on broilers' feed intake fed by aflatoxin B1 contaminated diet. Contrary to the present investigation, lower body weight gain, as well as reduced feed intake, were reported in chicks fed by aflatoxin B1 alone compared with the control group (Chand et al., 2011). The FCR in the first week in the PC group demonstrated a meaningful, higher value than the NC and SMS groups. Birds are likely to be more sensitive to aflatoxin B1 and its toxic effects in the early weeks (Da Silva Cardoso et al., 2016).

Chen et al. (2014) reported that serum uric acid and GGT levels were not significantly altered in chicks fed by aflatoxin. As shown, aflatoxicosis could alter the protein synthesis in broiler chickens, thereby decreasing the concentration of total plasma proteins, albumin and globulins (Solcan et al., 2013). Furthermore, several reports suggest that aflatoxin leads to significant variations in serum biochemical indices. Generally, the mentioned toxic effects of aflatoxin B1 on serum chemistry were based on the report announced by Solcan et al. (2013). As observed in this study, there was a meaningful enhancement in the serum levels of ALT and AST in chickens fed with an aflatoxin B1 contaminated diet. ALT (liver-specific) and AST (derived from other organs) are the key enzymes in liver cells (Amiri Dumari et al., 2014). As frequently reported, there was a simultaneous increase in ALT and AST in liver damage cases, similar to what has been demonstrated in this research. Following the necrosis or membrane permeability alteration, hepatic cell disruption may raise the AST and ALT enzymes' concentration (Ozer et al., 2008). In the liver, as the target organ, aflatoxin $\mathrm{B} 1$ is transformed into the reactive 8, 9-epoxide form, capable of binding RNA, DNA, and proteins. Such being the case, the toxin can promote liver damage, increasing liver weight (Bailey et al., 2006). We observed that the PC group gave rise to a substantial reduction in HDL and calcium levels in chick's serum compared with the other groups. As reported, HDL can eliminate cholesterol from peripheral tissues, even the good cholesterol, protecting the body against some diseases. As the findings indicate, intense exposure to high doses of aflatoxin B1 leads to liver damage and impaired lipid metabolism by changing the expression of lipid and lipoproteins' pertinent genes (Rotimi et al., 2017). The homeostasis of blood phosphorus and calcium levels are directly dependent on the kidney-intestinal axis and parathormone hormone (PTH). Glahn et al. (1991) reported the relationship between vitamin $\mathrm{D}$, phosphorus, and calcium, suggesting that it promoted a decline in the level of vitamin D, a reduction in PTH synthesis, the refuse in the feedback of kidney and intestine to PTH, and finally, an alteration in the blood phosphorus and calcium levels, directly or indirectly by these routes. The metabolism of AFB1 by the cytochrome P450 enzymes generates intracellular reactive oxygen species (ROS), including hydroxyl radical, hydrogen peroxide $\left(\mathrm{H}_{2} \mathrm{O}_{2}\right)$, and superoxide 
anion. ROS, and their by-products of lipid peroxidation, such as MDA, are noticed to induce lipid peroxidation in highly unsaturated fatty acids of the cell membrane (Rasouli-Hiq et al., 2016). Oxidative stress occurs when the level of ROS exceeds the tolerance capacity of the cellular antioxidant defense system (Palanivel et al., 2008). The following can increase MDA as the main index of lipid peroxidation: 1) AFB1 increases the free copper and iron levels in organs by stopping protein synthesis and reducing the concentration of ceruloplasmin and transferrin in the liver. Banding iron from outside and inside absorption causes a reduction of free iron levels, which acts as a mechanism to prevent lipid peroxidation (Shabani et al., 2016). 2) Reduction in vitamin concentration, especially vitamin A and $\mathrm{E}$ that play a role in the prevention of lipid peroxidation, can be one of the reasons for the increase of MDA levels (Shabani et al., 2016). 3) Changes in the activity of the antioxidant enzyme such as superoxide dismutase (SOD), catalase, and glutathione peroxidase $\left(\mathrm{GP}_{\mathrm{X}}\right)$ indirectly cause changes in the levels of MDA (Raei et al., 2021).

Our study results indicated that aflatoxin B1 damaged the immune system in aflatoxin B1-fed chickens. MTT assay, widely employed to measure cell proliferation, is based on mitochondrial respiratory chain activity (Mosmann, 1983). Zimmermann et al. (2014) showed that increasing ROS levels by aflatoxin B1 is probably subject to broiler chickens' health status. Bbosa et al. (2013) reported that aflatoxin B1 could decrease lymphocyte mitochondrial activity, possibly due to mitochondrial dysfunction. As Sahoo and Mukherjee (2001) reported, aflatoxins suppress the immune system by producing free radicals by neutrophils. Generally, the aflatoxin level, causing immunotoxicity, is less than the level that leads to a reduction in bird performance. Although the main bases for mycotoxins immunosuppressive effects are not recognized, the decrease in T or B cell activity, the impaired antibody production, the decreased complement or interferon activity, and regressed macrophage-effector cell role may be due to aflatoxins (Corrier, 1991). It is also assumed that aflatoxin besides affecting lymphocytes, reduces immunoglobulins production by non-specific effects on protein synthesis through inhibiting RNA polymerase, lipid peroxidation, and liver damage (Manafi et al., 2014 b).

In the previous years, the hypothesis of the medicinal herb's effect on alleviating the toxicity of aflatoxin has been proposed by some researchers (Tedesco et al., 2004; El-Nekeety et al., 2011; Hamzawy et al., 2012). The increasing concern in natural dietary ingredients has a centralized alarm on herbs applied as feed and food additive, a rich source of bio-nutrients or bio-active phytochemicals (El-Nekeety et al., 2011). Our results showed that supplementing the aflatoxin B1 contaminated diet by SMS, TV, and RO, or their combination, could improve biochemical factors. Additionally, as shown in the present study, an individual SMS or the combination of the other herbs could restore the adverse effects of feeding aflatoxin B1 on immune function. According to Tedesco et al. (2004), as the main component of milk thistle, silymarin could produce a defense against the toxicity of aflatoxin B1 in broiler chicks. Baer-Dubowska et al. (1998) reported that silymarin inhibiting the cytochrome $\mathrm{P} 450$ system could prevent aflatoxin B1 activation in the liver. The previous literature suggests that silymarin may exert its antioxidant effect in a variety of ways: regulating cell membrane stability and permeability, absorbing and regulating 
intracellular glutathione, inhibiting the transformation of hepatic stellate cells into myofibroblasts, and promoting DNA, RNA, and protein biosynthesis (Fraschini et al., 2002). Phenolic phytochemicals in some herbs, such as Thymus vulgaris, is likely to protect cellular compounds against free radicals via antioxidant activity, as well as free radical scavenging effects (El-Nekeety et al., 2011). Manafi et al. (2014 a) reported that broiler chicks fed by aflatoxin-contaminated diet with Rosmarinus officinalis restore aflatoxin's adverse effects. Besides, Hamzawy et al. (2012) reported that phenolic compounds in Thymus vulgaris could reduce aflatoxin's toxicity on the immune system. In general, the antioxidant activities in herbs and fruits may be pertinent to their phenolic compounds following their ability to eliminate peroxyl free radicals (Cao et al., 1997). Antioxidants' mechanism may contribute to scavenging and suppressing the free radicals' formation and peroxidation procedures (Manafi et al., 2014 a). In the current study, phenolic compounds, such as silymarin in Silybum marianum seed, thymol, and carvacrol in Thymus vulgaris, as well as borneol and camphor in Rosmarinus officinalis, have reduced the toxic effects of aflatoxin B1 by antioxidant activity.

\section{Conclusion}

Based on the results, it was found that the presence of aflatoxin B1 in the diet of young broiler chicks had a negative effect on blood parameters, lipid peroxidation, and immune function. Despite the positive effects of Silybum marianum seed, Thymus vulgaris, and Rosmarinus officinalis on some of the experiment parameters, further studies are needed to elucidate the causal mechanisms involved.

\section{Acknowledgments}

This project was supported by Urmia University. The funder has no role in the design, analysis or writing of this manuscript.

\section{References}

Amiri Dumari M., Sarir H., Fani Makki O., Afzali N. (2014). Effect of milk thistle (Silybum marianum L.) on biochemical parameters and immunity of broiler chicks fed aflatoxin B1 after three weeks. Iran J. Toxicol., 26: 1098-1103.

AOAC (2000). Aflatoxins in corn, almonds, Brazil nuts, peanuts, and pistachio nuts, multifunctional column (Mycosep) method. Natural toxins-chapter 49. Official Methods of Analysis of AOAC International, 17th edition, volume II, AOAC International, Gaithersburg, MD, USA.

B a er-Dubowska W., S za e fer H., Krajka-Kuzniak V. (1998). Inhibition of murine hepatic cytochrome $\mathrm{P} 450$ activities by natural and synthetic phenolic compounds. Xenobiotica, 28: 735-743.

B a il e y C.A., L a t i mer G.W., B arr A.C., Wigle W.L., Ha q A.U., B althrop J.E., Kube n a L.F. (2006). Efficacy of montmorillonite clay (NovaSil PLUS) for protecting full-term broilers from aflatoxicosis. J. Appl. Poultry Res., 15: 198-206.

B bos a G.S., Kitya D., Lubega A., Ogwal-Okeng J., A nokbonggo W.W., K ye gom b e D.B. (2013). Review of the biological and health effects of aflatoxins on body organs and body systems. Aflatoxins - Recent Advances and Future Prospects, 12: 239-265.

B e n zi e I.F.F., Strain J.J. (1996). The ferric reducing ability of plasma (FRAP) as a measure of "antioxidant power": the FRAP assay. Anal. Biochem., 239: 70-76. 
B oll in eni R.C., Guldvik I.J., G rönberg H., Wiklund F., Mills I.G., Thie de B. (2015). A differential protein solubility approach for the depletion of highly abundant proteins in plasma using ammonium sulfate. Analyst, 140: 8109-8117.

B ots oglou N.A., Fletour is D.J., Papageorgiou G.E., Vas silopoulos V.N., Mant i s A.J., Trak at ell i s A.G. (1994). Rapid, sensitive, and specific thiobarbituric acid method for measuring lipid peroxidation in animal tissue, food, and feedstuff samples. J. Agric. Food Chem., 42: 1931-1937.

B ro ok s R.L., B o u n o u s D.I., A n d re a s e n C.B. (1996). Functional comparison of avian heterophils with human and canine neutrophils. Comp. Hematol. Int., 6: 153-159.

C a o G., S o fi c E., P r i o r R.L. (1997). Antioxidant and prooxidant behavior of flavonoids: structure activity relationships. Free Radic. Biol. Med., 22: 749-760.

Chand N., Muhammad D., Durrani F.R., Subhan Qureshi M., Shahibzada S. (2011). Protective effect of milk thistle (Silybum marianum) against aflatoxin B1 in broiler chicks. Asian-Aust. J. Anim. Sci., 24: 1111-1118.

Chen X., Horn N., A p ple g a te T.J. (2014). Efficiency of hydrated sodium calcium aluminosilicate to ameliorate the adverse effects of graded levels of aflatoxin B1 in broiler chicks. Poultry Sci., 93: 2037-2047.

Choi H.S., Kim J.W., Cha Y.N., Ki m C. (2006). A quantitative nitroblue tetrazolium assay for determining intracellular superoxide anion production in phagocytic cells. J. Immunoass. Imunochem., 27: 31-44.

Corrie r D.E. (1991). Mycotoxicosis: mechanisms of immunosuppression. Vet. Immunol. Immunopathol., 30: 73-87.

Da Silva Cardoso V., Vermelho A.B., Ribeiro De Lima C.A., De Oliveira G.M., De Lima M.E.F., D a Silva L.H.P., D ire ito G.M., Miranda Danelli M.D.G. (2016). Antigenotoxic effect of piperine in broiler chickens intoxicated with aflatoxin B1. Toxins, 8: 316 .

D it t a Y.A., Mahad S., B a ch a U. (2019). Aflatoxins: their toxic effect on poultry and recent advances in their treatment. In: Mycotoxins: impact and management strategies, P.B. Njobeh, F. Stepman (eds). InTech: Rijeka, Croatia, 127 pp.

E1-Nekeety A.A., Mohamed S.R., Hathout A.S., Has an N.S., Aly S.E., Abdel- W a h h ab M.A. (2011). Antioxidant properties of Thymus vulgaris oil against aflatoxin-induced oxidative stress in male rats. Toxicon, 57: 984-991.

E 1 - N e zami H., Kanka an pa a P., S a $1 \mathrm{~m}$ ine n S., A hok as J. (1998). Ability of dairy strains of lactic acid bacteria to bind a common food carcinogen, aflatoxin B1. Food Chem. Toxicol., 36: 321-326.

Fraschini F., Demartini G., Esposti D. (2002). Pharmacology of silymarin. Clin. Drug Investig., 22: 51-65.

Glahn R.P., B e er s K.W., B ottje W.G., Wi de man R.F., Huff W.E., Tho mas W. (1991). Aflatoxicosis alters avian renal function, calcium, and vitamin D metabolism. J. Toxicol. Environ. Health, 34: 319-321.

Hamzawy A., E1-Denshary E.S.M., Hasan N.S., Manaa F., Abdel-Wahhab M.A. (2012). Antioxidant and hepatorenoprotective effects of Thyme vulgaris extract in rats during aflatoxicosis. Int. J. Pharmacol., 2: 106-117.

Hus sa in Z., Khan M.Z., Khan A., Javed I., S ale emi M.K., Mahmood S., A si M.R. (2010). Residues of aflatoxin B1 in broiler meat: Effect of age and dietary aflatoxin B1 levels. Food Chem. Toxicol., 48: 3304-3307.

Lo i M., Paciolla C., L ogri e co A.F., Mulè G. (2020). Plant bioactive compounds in pre- and postharvest management for aflatoxins reduction. Front. Microbiol., 11: 243-259.

Malekinezhad P., Ellestad L.E., A fzali N., Farhangfar S.H., Omidi A., Moham$\mathrm{m}$ a di A. (2020). Evaluation of berberine efficacy in reducing the effects of aflatoxin B1 and ochratoxin A added to male broiler rations. Poultry Sci., 100: 797-809.

Manafi M., Hedayati M., Yari M. (2014 a). Application of rosemary (Rosmarinus officinalis L.) essence on chicks fed aflatoxin B1: impacts on internal organ weights, biochemical traits and mortality. Zoology, 1: 13-19.

Man afi M., Hed a y at i M., Yari M. (2014 b). Aflatoxicosis and herbal detoxification: the effectiveness of thyme essence on performance parameters and antibody titers of commercial broilers fed aflatoxin B1. Res. Zool., 4: 43-50. 
M o s m a n n T. (1983). Rapid colorimetric assay for cellular growth and survival: application to proliferation and cytotoxicity assays. J. Immunol. Methods, 65: 55-63.

Naghdi Badi H., Yazdani D., S a jad Manazari F. (2004). Effects of spacing and harvesting time on herbage yield and quality/quantity of oil in thyme, Thymus vulgaris L. Ind. Crops Prod., 19: $231-236$.

Nakavuma J.L., Kirabo A., Bogere P., Nabulime M.M., Ka ya A.N., Gnonlon$\mathrm{f}$ in B., (2020). Awareness of mycotoxins and occurrence of aflatoxins in poultry feeds and feed ingredients in selected regions of Uganda. Int. J. Food Contam., 7: 1-10.

Oguz H., B ahcivan E., Erdogan T. (2018). Detoxification of aflatoxin in poultry feed: An update. Eurasian J. Vet. Sci., 27: 1-12.

O zer J., R a tn er M., Sh aw M., B a i l e y W., S ch o m a ker S. (2008). The current state of serum biomarkers of hepatotoxicity. Toxicology, 245: 194-205.

Palanivel M.G., Rajkapoor B., Kumar R.S., Einstein J.W., Kumar E.P., Kum a r M.R., K a v i th a K., K u m a r M.P., J a y a k a r B. (2008). Hepatoprotective and antioxidant effect of Pisonia aculeata L. against CCl4-induced hepatic damage in rats. Scientia Pharma., 76: 203-216.

P e p p ing J. (1999). Milk thistle: Silybum marianum. Am. J. Health Syst. Pharm., 56: 1195-1197.

R a e i H., K arimi Torshizi M.A., Sharafi M., A h m a di H. (2021). Improving seminal quality and reproductive performance in male broiler breeder by supplementation of camphor. Theriogenology, 166: 1-8.

Rasouli-Hiq A., Baghezadeh Kasmani F., Mehri M., Karimi Torshizi M.A. (2016). Nigella sativa (black cumin seed) as a biological detoxifier in diet contaminated with aflatoxin B1. J. Anim. Physiol. An. N., 101: 77-86.

Rot im i O.A., Rotimi S.O., D uru C.U., Eb e be inw e O.J., A b i o dun A.O., Oyen iy i B.O., F a d u y i l e F.A. (2017). Acute aflatoxin B1-induced hepatotoxicity alters gene expression and disrupts lipid and lipoprotein metabolism in rats. Toxicol. Rep., 4: 408-414.

S a h o o P.K., M u kh e r j e e S.C. (2001). Immunosuppressive effects of aflatoxin B1 in Indian major carp (Labeo rohita). Comp Immunol. Microb., 24: 143-149.

Shabani A., Dastar B., Has sani S., Khomeiri M., Shabanpour B. (2016). Decreasing the effects of aflatoxins on color and oxidative stability of broiler meats using nanozeolite. J. Agric. Sci. Technol., 18: 109-121.

Shotwell O.L., Hess eltine C., Stubblefield R., Sorenson W. (1966). Production of aflatoxin on rice. Appl. Microbiol., 14: 425-428.

Shushtari N., Abtahi Froushani S.M. (2017). Caffeine augments the Instruction of antiinflammatory macrophages by the conditioned medium of mesenchymal stem cells. Cell J., 19: 415-424.

Solcan C., Gogu M., Floristean V., Oprisan B., Solcan G. (2013). The hepatoprotective effect of sea buckthorn (Hippophae rhamnoides) berries on induced aflatoxin B1 poisoning in chickens. Poultry Sci., 92: 966-974.

Tedes co D., Ste idler S., Gallett i S., Taneni M., Sonzogni O., R avarotto L. (2004). Efficacy of silymarin-phospholipid complex in reducing the toxicity of aflatoxin B1 in broiler chicks. Poultry Sci., 83: 1839-1843.

Ts u k a m o t o H., Rip pe R., N i e m e lä O., L in M. (1995). Roles of oxidative stress in activation of Kupffer and Ito cells in liver fibrogenesis. J. Gastroen. Hepatol., 10: 50-53.

Zh a o J., Shirley R.B., D i bne r J.D., Ura ize e F., Officer M., K i t c hell M., Vazquez- A n o n M., Knigh t C.D. (2010). Comparison of hydrated sodium calcium aluminosilicate and yeast cell wall on counteracting aflatoxicosis in broiler chicks. Poultry Sci., 89: 2147-2156.

Z i m m e r mann C.E.P., M a cha do A.K., C a d oná F.C., J a que s J.A.S., S ch l e m m er K.B., L a u tert C., Cruz I.B.M., Z a n e t te R.A., L e a l D.B.R., S a n t u r i o J.M. (2014). In-vitro cytotoxicity of aflatoxin B1 to broiler lymphocytes of broiler chickens. Braz. J. Poultry Sci., 16: $307-312$.

Received: 4 IX 2020

Accepted: 15 IV 2021 